\title{
Assessment of Antioxidant Capacity, Anti-collagenase and Anti-elastase Assays of Malaysian Unfermented Cocoa Bean for Cosmetic Application Norliza Abdul Wahab ${ }^{1,3 *}$, Russly Abdul Rahman ${ }^{1}$, Amin Ismail $^{2}$, Shuhaimi Mustafa ${ }^{1}$ and Puziah Hashim ${ }^{1}$
}

${ }^{1}$ Halal Products Research Institute, Universiti Putra Malaysia, Putra Infoport, 43400 UPM Serdang, Selangor, Malaysia

${ }^{2}$ Department of Nutrition and Dietetics, Faculty of Medicine and Health Sciences, Universiti Putra Malaysia, 43400 UPM Serdang, Selangor, Malaysia

${ }^{3}$ Malaysian Cocoa Board, Cocoa Innovation \& Technology Centre, Lot Pt 12621, Nilai Industrial Park, 71800 Nilai, Negeri Sembilan, Malaysia.

\begin{abstract}
Recent trends in anti-aging research projected the use of antioxidant compound derived from botanical products. Phenolic acids, flavonoids and high molecular weight polyphenols are some of antioxidants which are able to protect human skin against the harmful effects of ultraviolet irradiation, i.e. photoaging and skin cancer development. Various studies have demonstrated cocoa beans to contain polyphenols and possess health promoting effects mainly on antiradical property. In this study, the HPLC/DAD quantification of (-)-epicatechin from PBC123 and PBC140 Malaysian unfermented cocoa bean extracts (CBEs) were 121.01 and $118.09 \mathrm{mg} / \mathrm{g} \mathrm{DW}$, whereas concentration of (+)-catechin were 6.65 and $6.53 \mathrm{mg} / \mathrm{g} \mathrm{DW}$, respectively with no significant differences $(p>0.05)$. In term of antioxidant capacity, Ferric reducing/antioxidant power of the respective clones were assayed at 822.10 and $795.99 \mathrm{mM} \mathrm{FeSO}_{4} / \mathrm{g} \mathrm{DW}$. Inhibition of proteinases expression induces by reactive oxygen species were exhibited in the anti-collagenase and anti-elastase assays. The anti-collagenase activity of PBC123 and PBC140 were $62.99 \%$ and $59.96 \%$ whereas anti-elastase has been measured at $36.60 \%$ and $15.75 \%$, respectively. Positive and high correlation were observed within epicatechin content (1), FRAP (2) and anti-collagenase (3) with significant relationships for both PBC123 and PBC140 ( $r 12=0.901$, $r 13=0.768$ and $r 23=0.908$ ). A statistical One-Way ANOVA showed that there was no significant difference obtained between PBC123 and PBC140 in terms of epicatechin, FRAP and anti-collagenase assays, however, significant difference was observed from anti-elastase assessment $(p<0.05)$. These results indicate unfermented PBC123 clone as a potential source of natural ingredient in a cosmetic industry.
\end{abstract}

\section{Introduction}

Malaysia was the fourth largest producer of cocoa worldwide in the early 1990's [1]. Unfortunately, declining of cocoa bean production in Malaysia since the decade has raised concern of economic viability and sustainability of the cocoa planting industry. Apart from low prices, Cocoa Pod Borer (CPB) infestation and labor issue which were often quoted as reasons for the loss of interest shown in the crop have been identified as the major factors responsible for its decline. Two potential Malaysian cocoa clones, namely $\mathrm{PBC} 140$ and $\mathrm{PBC} 123$, known for their high yield, i.e. 1,677 and 1,453 kg/ha/year, respectively and high resistance against Vascular Streak Disease (VSD) and CBP infestation, gained lot of attentions for the past few years [2]. Azizah et al. [3] in their study have reported that in accordance to the West African beans, Malaysian beans are traded at a lower price due to inadequate standard of cocoa aroma, astringency and bitter taste characteristics. One of the factors to such occurrence might be due to its high amount of phenolic substances. Moreover, unfermented beans contain significant amount of phenolic content (12-18\% w/w) [4] with $60 \%$ are comprised of flavanol monomers (epicatechin and catechin) and procyanidin oligomers (dimer to decamer).

Nowadays, the number of natural products that has been used for the development of skin care products is in the increasing trend. Most of these natural products have been proven to exhibit significant antioxidant [5], emollient (María Elena et al.,) [6] as well as for ultraviolet (UV) protection [7] which are crucial for skin care product formulation. The properties are most probably due to the presence of particular phytochemicals, e.g. an antioxidant, in the natural products as active compound. Moreover, natural ingredients are easier to be absorbed by the superficial layers of the skin, thus can lower skin allergy problems. An antioxidant is characterized by any chemical substance which, when observed at relatively low concentration in the body, could decrease or prevent oxidation of substrates [8]. Polyphenols were reported as one of the potent antioxidant besides other common dietary antioxidants, such as ascorbic acid, vitamin $\mathrm{E}, \boldsymbol{\beta}$-carotene and selenium. Epidemiological studies showed many of the polyphenols exhibit a wide range of biological effects such as an antibacterial, antiviral, anti-inflammatory, anti-allergic, antiradical, anti-aging, vitamin C protection against Reactive Oxygen Species (ROS) and reduction of $\alpha$-tocopheryl radical. There has been encouraging plant sources associated with polyphenols content like fruits, vegetables [9-11]. Cocoa beans have been said to contain significant amount of polyphenols particularly epicatechin and catechin which were reported as a potential candidate in free radicals scavenging either present in our body system or inner layer of the skin stratum corneum [12].

It is interesting to note that aging can be slowed down, or even stopped for a while and sometimes it can be reversed. Apparently, a study by Lee et al. (2012). on Labisia pumila exhibited that the antioxidant-containing extract worked as a photo protective agent against ROS attacks generated by UV exposure, hence extrinsic aging can be avoided. According to [13], polyphenols have been spectrophotometrically showed high antioxidant properties via free radical scavenging, Ferric Reducing Antioxidant Power (FRAP) and $\beta$-carotene bleaching activities and proven to be highly correlated with anti-collagenase and anti-elastase activities. In another study conducted on isolated green tea (Camellia sinensis), polyphenols such as catechin and epigallocatechin gallate have been found to be the inhibitors of collagenase and elastase, subsequently decreasing skin wrinkles [14]. Additionally, cocoa polyphenols have been proven

*Corresponding author: Norliza Abdul Wahab, Halal Products Research Institute Universiti Putra Malaysia, Putra Infoport, 43400 UPM Serdang, Selangor, Malaysia, Tel: 6016-6470-078; E-mail: naw@koko.gov.my

Received March 19, 2014; Accepted April 18, 2014; Published April 22, 2014

Citation: Wahab NA, Rahman RA, Ismail A, Mustafa S, Hashim P (2014) Assessment of Antioxidant Capacity, Anti-collagenase and Anti-elastase Assays of Malaysian Unfermented Cocoa Bean for Cosmetic Application. Nat Prod Chem Res 2 :132. doi:10.4172/2329-6836.1000132

Copyright: () 2014 Wahab NA, et al. This is an open-access article distributed under the terms of the Creative Commons Attribution License, which permits unrestricted use, distribution, and reproduction in any medium, provided the original author and source are credited. 
Citation: Wahab NA, Rahman RA, Ismail A, Mustafa S, Hashim P (2014) Assessment of Antioxidant Capacity, Anti-collagenase and Anti-elastase Assays of Malaysian Unfermented Cocoa Bean for Cosmetic Application. Nat Prod Chem Res 2 :132. doi:10.4172/2329-6836.1000132

Page 2 of 6

to exhibit a positive action on skin elasticity and skin tonus, namely glycosaminoglycans and collagen I, III and IV [12]. However, the studies of phenolic compounds localizing in Malaysian unfermented cocoa bean extract especially in delaying aging process are limited at presence. Thus, this investigation is aimed on the studies of total phenolics quantification, antioxidant capacity (AOC), anti-collagenase and anti-elastase characteristics of Malaysian unfermented cocoa bean extractas an active ingredient in wrinkle-care cosmetics.

\section{Materials and Methods}

\section{Standards and reagents}

Epicatechin, catechin, gallic acid, ascorbic acid, ferrous sulphate $\left(\mathrm{FeSO}_{4} \cdot 7 \mathrm{H}_{2} \mathrm{O}\right)$ and 2,4,6-tri(2-pyridyl)-1,3,5-triazine (TPTZ) were purchased from Sigma Chemical Co. (St. Louis, MO, USA); Folin-Ciocalteu reagent (FC), sodium carbonate, ferric chloride $\left(\mathrm{FeCl}_{3} \bullet 6 \mathrm{H}_{2} \mathrm{O}\right)$ and ethanol were obtained from Merck (Darmstadt, Germany); 4-(2-hydroxyethyl)-1-piperazineethanesulfonic acid (HEPES buffer), N-Isobutyl-N-(4-methoxyphenylsulfonyl)glycyl hydroxamic acid $(\mathrm{NNGH})$, elastatinal, fibroblast collagenase (matrix metalloproteinase-1, MMP-1), Ac-PLG-[2-mercapto-4-methylpentanoyl]-LG-OC2H5, human neutrophil elastase (metalloelastase, MMP-12) and MeOSuc-Ala-Ala-Pro-Val-pNA were purchased from Enzo Life Sciences (Enzo Life Sciences International, Inc., PA, USA).

\section{Plant material}

Fresh cocoa beans of Malaysian PBC123 and PBC140 clones were acquired from the Cocoa Research and Development Center, Malaysian Cocoa Board, Jengka, Pahang, Malaysia. The beans were immediately sun-dried for 4 consecutive days without fermentation. The dried and unfermented beans were later manually deshelled prior to grinding.

\section{Ethanolic extraction and High Performance Liquid Chromatography/ Diode Array Detector (HPLC/DAD) determination of epicatechin and catechin}

The extract was prepared according to the method of [15], with a slight modification. The seeds were ground in a high-speed laboratory mill until the particle size was reduced to $\sim 1 \mathrm{~mm}$. Lipids were removed from $100 \mathrm{~g}$ of the ground seeds by extracting three times with $450 \mathrm{~mL}$ of hexane. The lipid-free solids were air-dried to yield $45 \mathrm{~g}$ of fat-free material. Ground cocoa cotyledons were further extracted with $70 \%$ aqueous ethanol for $2 \mathrm{~h}$ at $50^{\circ} \mathrm{C}$ using an orbital shaker (Unimax 1010, Heidolph, Germany). The ratio between samples to extraction medium was 1:25. The extracts were combined, and the organic solvent was removed by rotary evaporator (IKA ${ }^{\circledR}$ RV 10 control, Staufen, Germany) under partial vacuum at $40^{\circ} \mathrm{C}$. The aqueous extracts were lyophilized and kept in air-tight container for further studies.

Ten (10) mg of dried sample material was mixed with $5 \mathrm{~mL} \mathrm{100 \%}$ methanol before injected through a reverse-phase $\mathrm{C}_{18}$ SEP-PAK cartridge (Waters Associates, Milford, MA). Epicatechin and catechin retained in the cartridge were eluted with $10 \mathrm{~mL} 40 \%$ aqueous methanol whereas $10 \mu \mathrm{L}$ of this solution were injected into the HPLC/DAD. The HPLC/DAD included a Waters Associates model 6000-A pump, U6K Universal injector, and Model 450 variable wavelength detector. Separation of epicatechin and catechin were accomplished on a reversephase analytical column with a mobile phase of water:methanol:acetic acid (87:8:5) pumped at a flow rate of $1.5 \mathrm{~mL} / \mathrm{min}$. The eluting epicatechin and catechin were detected by monitoring absorbance at $280 \mathrm{~nm}$ and quantified by comparing peak area of the sample to those obtained from authentic standards (Sigma, Co. Chemical, St. Louis, USA).

\section{Total phenolic content}

The Total Phenolic Content (TPC) was determined using the method developed by [16] with some modifications. The extract (100 $\mu \mathrm{L}$ ) was mixed with $0.75 \mathrm{~mL}$ of $\mathrm{FC}$ reagent (10-fold dilution with distilled water) and allowed to stand at $22^{\circ} \mathrm{C}$ for $5 \mathrm{~min}$. Then, 0.75 $\mathrm{mL}$ of sodium carbonate $(60 \mathrm{~g} / \mathrm{L})$ solution was added to the mixture. Following $90 \mathrm{~min}$ at $22^{\circ} \mathrm{C}$, absorbance was measured at $725 \mathrm{~nm}$ using a UV-visible spectrophotometer (UV 1601, Shimadzu Co., Ltd., Kyoto, Japan). Gallic acid at concentrations of $0.02-0.1 \mathrm{mg} / \mathrm{mL}$ was used as a standard. TPC was expressed as Gallic Acid Equivalent (GAE) per gram of dried sample.

\section{Ferric reducing/antioxidant power (FRAP) assay}

The ferric reducing power of the extract was determined based on the reduction of ferric-TPTZ to blue ferrous-TPTZ colored measured at $593 \mathrm{~nm}$. A high FRAP value indicates high antioxidant capacity. First, FRAP reagent was prepared as described by Benzie and Strain (1996). FRAP reagent $(1.8 \mathrm{~mL})$ was pipetted into a test tube and incubated at $37^{\circ} \mathrm{C}$ in a water bath for $10 \mathrm{~min}$. Then, absorbance was taken as $t_{0}$. Immediately, $100 \mu \mathrm{L}$ of sample or standard and $100 \mu \mathrm{L}$ of distilled water were added to the test tube, mixed and incubated at $37^{\circ} \mathrm{C}$ for $4 \mathrm{~min}$. Then, the absorbance was taken at $593 \mathrm{~nm}\left(t_{4}\right)$. The FRAP value was calculated based on the equation described by Benzie and Strain (1996) [17]. The reducing potential of the sample extract from unfermented cocoa bean extracts was determined against a standard curve of ferrous sulphate $(200-1000 \mathrm{mM})$ and the FRAP value was expressed as $\mathrm{mM} \mathrm{FeSO}_{4}$ equivalents per gram of dried sample.

\section{Collagenase assay}

The assay employed was based on spectrophotometric methods reported in the literature [18] with some modifications for use in a 96-well microplate reader. The assay was performed in $50 \mathrm{mM}$ HEPES buffer. MMP-1 was diluted in assay buffer to $2.5 \%(\mathrm{v} / \mathrm{v})$ whereby required total volume was $20 \mu \mathrm{L}$ per well. The mixture is warmed to reaction temperature at $37^{\circ} \mathrm{C}$ shortly before assay. Synthetic chromogenic substrate, (Ac-PLG-[2-mercapto-4-methyl-pentanoyl]-LG-OC $\mathrm{H}_{5}$ ) was dissolved in assay buffer to $4 \%(\mathrm{v} / \mathrm{v})$ and warmed at $37^{\circ} \mathrm{C}$ as well. The unfermented CBEs of $\mathrm{PBC} 123$ and $\mathrm{PBC} 140$ were incubated with MMP-1 in buffer for 15 minutes prior to substrate addition to start the reaction. Positive controls were performed with NNGH and ascorbic acid whereas negative controls were performed without any inhibitor. Absorbance at $412 \mathrm{~nm}$ was measured immediately after substrate addition and then continuously for 20 minutes in a microplate reader. Experiments were performed in triplicate and percentage of inhibitor activity remains were calculated using the equation below whereas samples ritual is summarized in Table 1 .

$$
\begin{aligned}
& \text { Inhibitor activity remaining }(\%)=\left(\mathrm{V}_{\text {inhibitor }} / \mathrm{V}_{\text {control }}\right) \times 100 \\
& \text { Velocity reaction of inhibitor, } \mathrm{V}_{\text {inhibitor }}=\text { Absorbance }{ }_{\text {inhibitor }} / \mathrm{min}_{\text {inhibitor }} \\
& \text { Velocity reaction of control, } \mathrm{V}_{\text {control }}=\text { Absorbance } \\
& \text { control }
\end{aligned}
$$

\section{Elastase assay}

This assay was performed in $100 \mathrm{mM}$ HEPES buffer. MMP-12 and chromogenic substrate, MeOSuc-Ala-Ala-Pro-Val-pNA were dissolved to $1.11 \%$ and $10 \%(\mathrm{v} / \mathrm{v})$ dilution, respectively, in the assay buffer and warmed to reaction temperature $\left(37^{\circ} \mathrm{C}\right)$. The unfermented CBEs of $\mathrm{PBC} 123$ and $\mathrm{PBC} 140$ were incubated with elastase for 10 minutes prior to substrate intervention to start the reaction. The final reaction mixture $(100 \mu \mathrm{L})$ contained buffer, $22 \mu \mathrm{U} / \mu \mathrm{L}$ elastase, $2 \mathrm{mM}$ substrate and $1000 \mu \mathrm{g} / \mathrm{mL}$ of the test extracts. Positive controls were 
Citation: Wahab NA, Rahman RA, Ismail A, Mustafa S, Hashim P (2014) Assessment of Antioxidant Capacity, Anti-collagenase and Anti-elastase Assays of Malaysian Unfermented Cocoa Bean for Cosmetic Application. Nat Prod Chem Res 2 :132. doi:10.4172/2329-6836.1000132

\begin{tabular}{|c|c|c|c|c|c|}
\hline Sample & $\begin{array}{c}\text { Assay } \\
\text { buffer } \\
(\boldsymbol{\mu L})\end{array}$ & $\begin{array}{c}\text { MMP-1 } \\
{[\mathbf{7 6 5} \mathbf{~ m} \mathbf{U} /} \\
(\boldsymbol{\mu L}](\boldsymbol{\mu L})\end{array}$ & $\begin{array}{c}\text { Inhibitor } \\
{[\mathbf{6 . 5} \boldsymbol{\mu} \mathbf{M}]} \\
(\boldsymbol{\mu L})\end{array}$ & $\begin{array}{c}\text { Substrate } \\
{\left[\begin{array}{c}\mathbf{m M}] \\
(\boldsymbol{\mu L})\end{array}\right.}\end{array}$ & $\begin{array}{c}\text { Total } \\
\text { Volume } \\
(\boldsymbol{\mu L})\end{array}$ \\
\hline Blank & 90 & 0 & 0 & 10 & 100 \\
\hline Negative control & 70 & 20 & 0 & 10 & 100 \\
\hline NNGH & 50 & 20 & 20 & 10 & 100 \\
\hline Ascorbic acid & 50 & 20 & 20 & 10 & 100 \\
\hline PBC 123 & 50 & 20 & 20 & 10 & 100 \\
PBC 140 & 50 & 20 & 20 & 10 & 100 \\
\hline
\end{tabular}

Table 1: Samples ritual for inhibition of collagenase assay.

performed with elastatinal and ascorbic acid whereas negative controls were performed without any inhibitor. Absorbance at $405 \mathrm{~nm}$ was measured immediately after substrate addition and then continuously for 10 minutes in a microplate reader. The inhibitor activity remaining (\%) of elastase is as the same as collagenase determination. Samples ritual is summarized as follows in Table 2.

\section{Statistical Analysis}

Data were expressed as mean \pm standard deviation of triplicates. One-way ANOVA (Minitab version 14.0) was used to determine the mean differences for epicatechin and catechin quantification, FRAP, anti-collagenase and anti-elastase activities of PBC123 and PBC140 clones at a significance level of $\mathrm{p}<0.05$. Pearson's correlation ( $r$-value) was used to determine correlation within epicatechin content, FRAP and anti-collagenase activity.

\section{Results and Discussions}

\section{TPC and profiling}

Traditional and hybrid cocoa beans were sampled and phenolic compounds extracted into $70 \%$ aqueous ethanol. The total extracted phenolics were then quantified. Table 3 demonstrates the TPC, expressed as gallic acid equivalent (mg GAE/g on a dry weight basis) and concentration of epicatechin and catechin determined in 2 Malaysian unfermented CBEs, namely $\mathrm{PBC} 123$ and $\mathrm{PBC} 140$. The results were compared with fermented cocoa beans from different countries conducted by [3] under the same condition of $70 \%$ ethanol aqueous extraction. Phenolic compounds undergo a complex redox reaction with the phosphotungstic and phosphomolybdic acids present in the FC reagent [19]. However, it should also be noted that some chemical group of ascorbic acid, organic acids, sugars, aromatic amines could also react with FC reagent [20]. In term of the TPC, there is no significant difference between PBC123 (200.85 $\pm 3.85 \mathrm{mg} \mathrm{GAE} / \mathrm{g} \mathrm{DW})$ and PBC140 (200.79 $\pm 3.27 \mathrm{mg} \mathrm{GAE} / \mathrm{g} \mathrm{DW})(p>0.05)$. On the contrary, TPC measured from both unfermented cocoa beans of PBC123 and PBC140 significantly exhibited enormous values when compared to the ones from fermented beans, regardless of the countries of origin (Table 3). Both of the unfermented clones showed as high as 200 -fold of TPC in comparison to the fermented beans. The high content of TPC in unfermented cocoa beans of $\mathrm{PBC} 123$ and $\mathrm{PBC} 140$ might account for the better results found for their antioxidant capacity. Several studies have revealed that the phenolic content in plants are associated with their antioxidant capacities, probably due to their redox properties, which allowed them to act as reducing agents, hydrogen donors, and singlet oxygen quenchers [21]. In general, our data indicate that the TPC of unfermented cocoa bean extracts could serve as a significant source for natural antioxidant.

Whilst TPC may be a useful indicator of potential nutritional benefit, the actual profile of phenolics within the bean is likely to be more important. Thus, profile of the extractable phenolics was determined by HPLC/DAD. Epicatechin and catechin content were identified by its chromatographic behavior and UV spectra $(280 \mathrm{~nm})$. The concentration of epicatechin in PBC123 and PBC140 were 121.01 \pm 2.19 and $118.09 \pm 1.14 \mathrm{mg} / \mathrm{g} \mathrm{DW}$, respectively whereas catechin content determined in the respective clones were $6.65 \pm 0.88$ and 6.53 $\pm 0.09 \mathrm{mg} / \mathrm{g}$ DW. It is well established that epicatechin is the main polyphenols found in cocoa beans [3,22,23]. For comparison, the content of epicatechin in Malaysian unfermented cocoa beans was at least 14-, 39-, 42- and 10-fold higher than the Malaysian, Ghanaian, Cote d'Ivoire and Sulawesian fermented cocoa beans, respectively (Table 3). A One-Way ANOVA for epicatechin showed that, there was no significant difference obtained between PBC140 and PBC123 ( $p>0.05$ ). Epicatechin is a major component of the polyphenols in cocoa beans and it is a monomer of procyanidins. Approximately, $35 \%$ of the TPC in unfermented cocoa beans is constituted of epicatechin. Unfermented refers to the beans that are sun-dried without fermentation or fermented only 1 to 2 days. Fermentation process will lower the polyphenol content through oxidation and exudation, thus, reducing astringency and bitterness [24]. Furthermore, 6-17\% of epicatechin is degraded during fermentation process in a study conducted by Nazaruddin et al. (2006) [25]. Therefore, unfermented cocoa beans would rather be chosen in this study due to its high epicatechin content as compared to fermented beans regardless of the quick process being encountered.

\section{Antioxidant capacity based on FRAP assay}

FRAP assay measures the reducing potential of an antioxidant reacting with a ferric tripyridyltriazine $\left(\mathrm{Fe}^{3+}-\mathrm{TPTZ}\right)$ complex and producing a colored ferrous tripyridyltriazine ( $\left.\mathrm{Fe}^{2+}-\mathrm{TPTZ}\right)$ [17]. Generally, the reducing properties are associated with the presence of compounds which exert their action by breaking the free radical chain and donating a hydrogen atom. The reduction of $\mathrm{Fe}^{3+}-\mathrm{TPTZ}$ complex to blue-colored $\mathrm{Fe}^{2+}-\mathrm{TPTZ}$ occurs at low $\mathrm{pH}$ which can be detected at $593 \mathrm{~nm}$. Figure 1 presents the dose-dependent ferric-reducing powers of sample extracts and the standard (ascorbic acid). Reducing power

\begin{tabular}{|c|c|c|c|c|c|}
\hline Sample & $\begin{array}{c}\text { Assay buffer } \\
(\boldsymbol{\mu L})\end{array}$ & $\begin{array}{c}\text { MMP-12 } \\
{[\mathbf{3 5} \mathbf{~ m U / \mu L}]} \\
(\boldsymbol{\mu L})\end{array}$ & $\begin{array}{c}\text { Inhibitor } \\
{[\mathbf{6 . 5} \boldsymbol{\mu M}]} \\
(\boldsymbol{\mu L})\end{array}$ & $\begin{array}{c}\text { Substrate } \\
{[\mathbf{1} \mathbf{m M}]} \\
(\boldsymbol{\mu L})\end{array}$ & $\begin{array}{c}\text { Total } \\
\text { Volume } \\
(\boldsymbol{\mu L})\end{array}$ \\
\hline Blank & 95 & 0 & 0 & 5 & 100 \\
\hline Negative control & 85 & 10 & 0 & 5 & 100 \\
\hline Elastatinal & 65 & 10 & 20 & 5 & 100 \\
\hline Ascorbic acid & 65 & 10 & 20 & 5 & 100 \\
\hline PBC 123 & 65 & 10 & 20 & 5 & 100 \\
PBC 140 & 65 & 10 & 20 & 5 & 100 \\
\hline
\end{tabular}

Table 2: Samples ritual for inhibition of elastase assay.

\begin{tabular}{|c|c|c|c|}
\hline \multicolumn{2}{|c|}{ Sample } & $\begin{array}{c}\text { Total Phenolic } \\
\text { Content } \\
\text { (mg GAE/g DW) }\end{array}$ & $\begin{array}{c}\text { Epicatechin } \\
\text { Content } \\
\text { (mg/g DW) }\end{array}$ \\
\hline${ }^{*}$ Fermented & $\begin{array}{c}\text { Malaysian } \\
\text { Ghanaian } \\
\text { Cote d'Ivoire }\end{array}$ & $0.11 \pm 0.01^{\mathrm{b}}$ & $8.2 \pm 0.12^{\mathrm{b}}$ \\
& Sulawesian & $0.09 \pm 0.02^{\mathrm{b}}$ & $3.0 \pm 0.16^{\mathrm{b}}$ \\
& $0.09 \pm 0.04^{\mathrm{b}}$ & $2.8 \pm 0.05^{\mathrm{b}}$ \\
& Malaysian PBC123 & $200.85 \pm 3.85^{\mathrm{a}}$ & $121.01 \pm 0.07^{\mathrm{b}}$ \\
& Malaysian PBC140 & $200.79 \pm 3.27^{\mathrm{a}}$ & $118.09 \pm 1.14^{\mathrm{a}}$ \\
\hline
\end{tabular}

Values are expressed as mean \pm standard deviation $(n=3)$. Means with different letters in a same column were significantly different $(p<0.05)$.

*Study conducted by Azizah et al. [3]

${ }^{* *}$ Results of present study

Table 3: Total phenolic content expressed as $\mathrm{mg}$ gallic acid equivalent/g dry weight and epicatechin content in fermented and unfermented cocoa beans from different countries. 


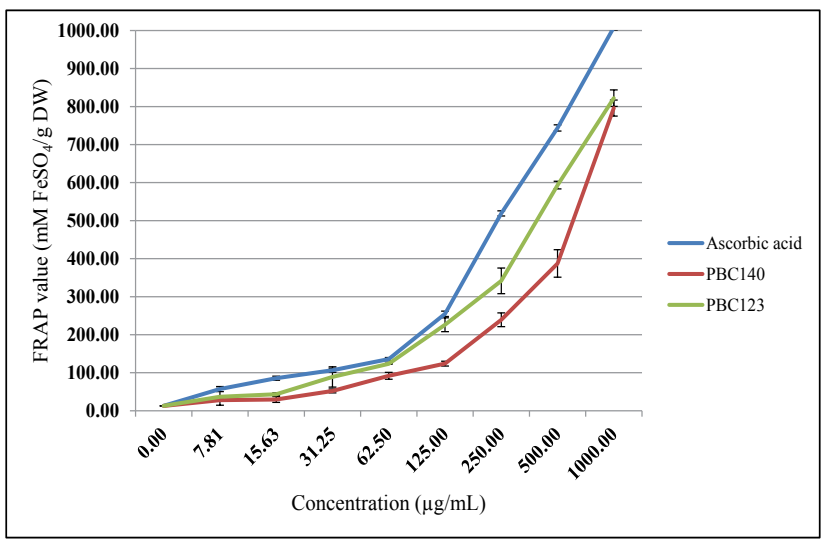

Figure 1: Antioxidant capacity of unfermented CBEs assayed by FRAP. Concentration of samples ranged from $0.00 \sim 1000.00 \mu \mathrm{g} / \mathrm{mL}$. Values are expressed as mean \pm standard deviation $(n=3)$. Means with different letters were significantly difference at the level of $p<0.05$

of all sample extracts and ascorbic acid increased with increasing concentration. The FRAP value of $\mathrm{PBC} 123$ and $\mathrm{PBC} 140$ were assayed at 822.10 and $795.99 \mathrm{mM} \mathrm{FeSO}_{4} / \mathrm{g} \mathrm{DW}$, respectively with no significant difference ( $p>0.05)$. According to Misnawi, et al. [24], Malaysian beans are well-known to have a low cotyledon $\mathrm{pH}$, hence the high antioxidant capacity of unfermented Malaysian cocoa beans of $\mathrm{PBC} 123$ and $\mathrm{PBC} 140$ could be due to the highly acidic (low $\mathrm{pH}$ ) nature of the bean cotyledon, which may influence the $\mathrm{pH}$ of the assay medium.

The reducing power of the studied extracts based on this assay supported the results conducted by Jinap et al. [26]. According to their studies, the unfermented Sulawesian and Malaysian beans which are well-known to have a low cotyledon $\mathrm{pH}$, exhibited the highest antioxidant capacity in comparison to fermented Ghanaian and Cote d'Ivoire beans. Azizah et al. [27] have also found high correlation between the epicatechin and antioxidant capacity of cocoa bean extracts. These findings are in agreement with the present result where the high FRAP value of unfermented PBC123 and PBC140 could have been contributed from the high epicatechin content as shown in Table 3.

\section{Inhibition of collagenase and elastase activities}

Collagenase and elastase are known to be major enzymes responsible for dehydration and wrinkle formation on the skin surface. The inhibitory effects of unfermented cocoa bean extracts on these two enzymes are shown in Figure 2. The inhibition of collagenase activities were not significantly different among the NNGH (68.05\%), ascorbic acid (64.08\%) as well as for PBC123 (62.99\%) and PBC140 (59.96\%). The elastase inhibitory effects for PBC123 and PBC140 were $36.60 \%$ and $15.75 \%$, respectively. This result showed that $\mathrm{PBC} 123$ and $\mathrm{PBC} 140$ have significantly higher inhibition effect on collagenase rather than on elastase, which could therefore contribute to anti-wrinkle effect. Collagen and elastin are major components of the connective tissue of the skin. Collagen accounts for $70-80 \%$ of the skin weight, providing structural stability. However, collagen is known to be rapidly dismantled by collagenase [28]. As collagenase is a zinc-containing metalloproteinase, the epicatechin within the unfermented cocoa bean extract which is also known to be a metal chelator compound, may bind to the $\mathrm{Zn}^{2+}$ ion within the enzyme, thus preventing it from binding with the substrate (collagen embedded within the dermis layer of the skin) [29]. As a result, hydrolyzable collagen can now be avoided and could therefore improve aging skin.
Plant phenolic compounds have been known to inhibit collagenase activity [30], accompanied by the reducing power of phenolic compounds to control aging. Cocoa polyphenols, epicatechin and catechin have been proven to exhibit positive action on skin elasticity and skin tonus, namely glycosaminoglycans and collagen 1, III and IV [12]. Moreover, persimmon (Diospyros kaki) leaf-derived polyphenols have showed anti-collagenase and anti-elastase activities [31]. Rosemary (Rosmarinus officinalis) extract has also been known to have strong anti-elastase activity [32]. The principle compound responsible for this inhibitory activity is considered to be the flavonoids present in plant extracts. According to Madhan et al. [33], the conformational change in collagenase induced by the green tea polyphenols is responsible for the inhibition of Clostridium histolyticum collagenase I. In this study, similar kinetic of action was exhibited from the high inhibition of collagenase activity from the Malaysian unfermented cocoa bean extracts of PBC123 and PBC140 (Figure 2A). The hydroxyl part of polyphenols can form hydrogen bond with the functional groups of collagenase. The benzene group of the polyphenols can also be involved in hydrophobic interactions with collagenase.

Elastin, an insoluble fibrous protein, occupies only $2-4 \%$ of the dermis matrix, but plays an important role in presenting the elasticity of the skin. It also comprises a network with collagenous fibers under the epidermis [34]. It is usually degraded by elastase, which can hydrolyze peripheral and structural proteins in the connective tissue.
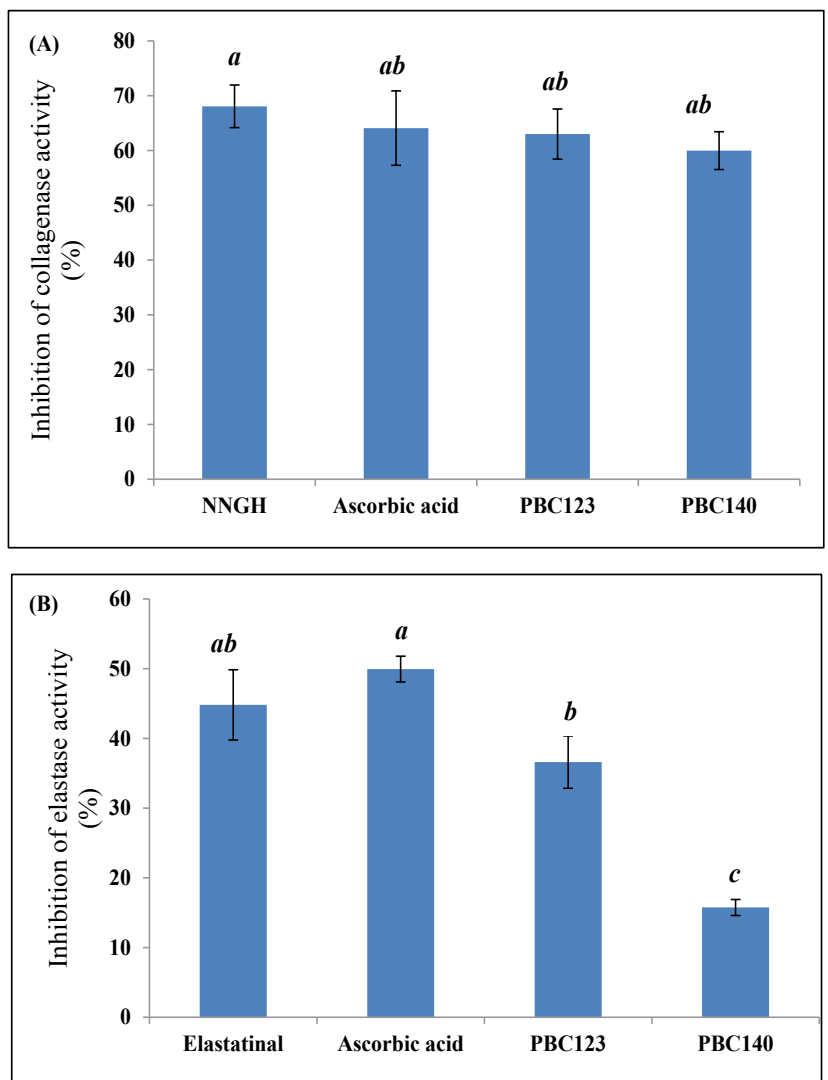

Figure 2: (A) Collagenase and (B) elastase inhibitory activities of Malaysian unfermented cocoa bean extracts. Inhibition of collagenase activity remaining $(\%)=\left(V_{\text {nibitor }} / \mathrm{V},\right) \times 100$. The percentage of elastase inhibition was calculated using the same method used for collagenase inhibition. Bars are means \pm standard deviation of three determinations. Different alphabetical indicates significant differences $(p<0.05)$ among samples by Fisher's multiple range tests. 
Citation: Wahab NA, Rahman RA, Ismail A, Mustafa S, Hashim P (2014) Assessment of Antioxidant Capacity, Anti-collagenase and Anti-elastase Assays of Malaysian Unfermented Cocoa Bean for Cosmetic Application. Nat Prod Chem Res 2 :132. doi:10.4172/2329-6836.1000132

Page 5 of 6

Because decomposition of elastin results from activation of elastase caused by the UV light or ROS, inhibition of elastase activity could also be a therapeutic target to protect elastin-induced skin aging.

Our results indicate that $\mathrm{PBC} 123$ and $\mathrm{PBC} 140$ possess equivalent effect on collagenase, however, the inhibition of elastase by $\mathrm{PBC} 123$ (36.60\%) was significantly $(p<0.05)$ higher than PBC140 (15.75\%). ROS is known to induce expression of proteinases, which cause remodeling of skin extracellular matrix. Activation of such proteases (e.g., matrix metalloproteinases and serine proteases) may be involved in the lack of skin elasticity [35]. The inhibitory effect of PBC123 on elastase could be reflected to our data, which showed slightly higher epicatechin content in PBC123 (Table 3). PBC123 can strongly interact with elastase than $\mathrm{PBC} 140$ may be due to hydrophobic interactions, providing the conformational change of elastase, resulting in stronger inhibition of elastase activity. Therefore, our results indicate that PBC123 as a beneficial ingredient in order to treat the effect of aging skin.

\section{Correlations}

Finally, correlations were tested to link the different analyzed parameters throughout this study (Table 4). High correlations were found between FRAP values on the one hand and epicatechin $(r=0.901, p<0.05)$ or anti-collagenase $(r=0.908, p<0.05)$ on the other. The FRAP technique used for determining antioxidant capacity has been proven to exhibit high correlation with phenolic compounds in different plants. It has been noted that phenolic compounds, which are known as hydrophilic antioxidants, are secondary metabolites that are mostly abundant in unfermented cocoa bean. Gil et al. [36] found high correlation $(r>0.90, p<0.05)$ between antioxidant capacity as determined by FRAP assay and phenolic compounds in nectarines, peaches and plums. Moreover, several studies have found that there were high correlation between total phenolic and antioxidant capacity for cereals [37,38]. A high correlation was also observed between phenolic compounds and antioxidant activity in fruit juices as determined by FRAP or electron spin resonance spectroscopy [39]. In this study, a good correlation between epicatechin and anti-collagenase was found $(r=0.768, p<0.05)$ suggested that epicatechin content in unfermented cocoa bean extract has allowed significantly $(p<0.05)$ increasing level of FRAP, anti-collagenase and anti-elastase activities as exhibited in Table 4. However, inhibition of elastase was not correlated neither with FRAP nor anti-collagenase activity.

\section{Conclusion}

In conclusion, the unfermented CBEs of $\mathrm{PBC} 123$ and $\mathrm{PBC} 140$ are capable of inhibiting collagenase, however elastase is poorly inhibited especially from PBC140. We presume that the enzymes inhibitory effects of unfermented cocoa bean extracts are dependent on their phenolic composition particularly epicatechin content,and molecular structures that define their reactivity towards the ferric reduction potential of sample extracts, as well as on the phenolic concentrations. The epicatechin may bind to the $\mathrm{Zn}^{2+}$ ion within the enzyme, thus preventing it from binding with the substrate and the hydroxyl part of polyphenols which form hydrogen bond with the functional groups of collagenase could therefore inhibit the acceleration of aging skin. Finally, the present study suggests that phenolic compounds of unfermented CBEs provide a good source of natural antioxidant that offer potential protective effect against fibroblast collagen deterioration and which could be exploited by the cosmetics industry.

\section{Acknowledgement}

\begin{tabular}{|l|c|c|c|c|}
\hline & Epicatechin & FRAP & Anti-collagenase & Anti-elastase \\
\hline Epicatechin & 1 & & & \\
FRAP & $0.901^{*}$ & 1 & & \\
Anti-collagenase & $0.768^{*}$ & $0.908^{*}$ & 1 & \\
Anti-elastase & $0.631^{*}$ & $0.383^{\text {ns }}$ & $0.064^{\text {ns }}$ & 1 \\
\hline
\end{tabular}

${ }^{*}$ Correlations significant at $p<0.05$

${ }^{n s}$ Non-significant

Table 4: Pearson's correlation coefficients $(r)$ among the analyzed parameters.

This research was supported financially by the Ministry of Science, Technology and Innovation of Malaysia (MOSTI) (Project No.: 02-03-13-SF0074). The authors would like to extend their thanks to Universiti Putra Malaysia (UPM) and Chemistry and Technology Division of Malaysian Cocoa Board for the laboratory facilities provided.

\section{References}

1. ICCO (2007) Quarterly bulletin of cocoa statistics. Vol. XXXIII, No. 1, Cocoa Year 2006/2007. International Cocoa Organization.

2. Azhar I, Lee, MT (2004) Perspective for cocoa cultivation in Malaysia: re-look at the economic indicators. Malaysian Cocoa Journal 1: 1-18.

3. Azizah O, Amin I, Nawalyah AG, Ilham A (2007) Antioxidant capacity and phenolic content of cocoa beans. Food Chemistry 100: 1523-1530.

4. Kim A, Keeny PG (1984) (-)-Epicatechin content in fermented and unfermented cocoa beans. Journal of Food Science 49: 1090-1092.

5. Saravi MS (2010) The chemistry, pharmacology and clinical properties of Sambucus ebulus: a review. Journal of Medicinal Plants Research 4: 96-103.

6. María Elena CMF, Soengas P, Velasco P, et al. (2011) Phenolic compounds in brassica vegetables. Molecules 16: 251-280.

7. Perona JS, Cabello-Moruno R, Ruiz-Gutierrez V (2006) The role of virgin olive oil components in the modulation of endothelial function. J Nutr Biochem 17 429-445.

8. Halliwell B, Gutteridge JMC (1999) Free radicals in biology and medicine United Kingdom: Oxford University Press.

9. Allaith AAA (2008) Antioxidant activity of Bahraini date palm (Phoenix dactylifera L.) fruit of various cultivars. International Journal of Food Science and Technology 43: 1033-1040.

10. Amin I, Zamaliah MM, Chin WF (2004) Total antioxidant activity and phenolic content in selected vegetables. Food Chemistry 87: 581-586.

11. Dreosti IE (2000) Antioxidant polyphenols in tea, cocoa, and wine. Nutrition 16: 692-694

12. Gasser P, Lati E, Peno-Mazzarino L, Bouzoud D, Allegaert L, et al. (2008) Cocoa polyphenols and their influence on parameters involved in ex vivo skin restructuring. Int J Cosmet Sci 30: 339-345.

13. Young HK, Chan BC, Jin GK, Kang IK, Sun HP, et al. (2008) Anti-wrinkle activity of ziyuglycoside I isolated from a Sanguisorba officinalis root extract and its application as a cosmeceutical ingredient. Bioscience Biotechnology and Biochemistry 72: 303-311.

14. Yang HH, Eun YJ, Dong ON, Hyung JS (2014) Physiological effects of formulation containing tannase-converted green tea extract on skin care: physical stability, collagenase, elastase, and tyrosinase activities. Integrative Medicine Research.

15. Hammerstone JF, Lazarus SA, Mitchell AE, Rucker R, Schmitz HH (1999) Identification of procyanidins in cocoa (Theobroma cacao) and chocolate using high-performance liquid chromatography/mass spectrometry. J Agric Food Chem 47: 490-496.

16. Singleton VL, Rossi JA (1965). Colorimetry of total phenolics with phosphomolybdic-phosphotungstic acid reagents. American Journal of Enology and Viticulture 16: 144-158

17. Benzie IF, Strain JJ (1996) The ferric reducing ability of plasma (FRAP) as a measure of "antioxidant power": the FRAP assay. Anal Biochem 239: 70-76.

18. Weingarten H, Feder J (1985) Spectrophotometric assay for vertebrate collagenase. Anal Biochem 147: 437-440.

19. Prasad NK, Divakar S, Shivamurthy GR, Aradhya SM (2005) Isolation of free radical scavenging antioxidant from water spinach (Ipomoea aquatic Forsk). 
Citation: Wahab NA, Rahman RA, Ismail A, Mustafa S, Hashim P (2014) Assessment of Antioxidant Capacity, Anti-collagenase and Anti-elastase Assays of Malaysian Unfermented Cocoa Bean for Cosmetic Application. Nat Prod Chem Res 2 :132. doi:10.4172/2329-6836.1000132

Page 6 of 6

Journal of Science Food and Agriculture 85: 1461-1468.

20. Meda A, Lamien CE, Romito M, Millogo J, Nacoulma OG (2005) Determination of the total phenolic, flavonoid and proline contents in Burkina Fasan honey, as well as their radical scavenging activity. Food Chemistry 91: 571-577.

21. Chang ST, Wu JH, Wang SY, Kang PL, Yang NS, et al. (2001) Antioxidant activity of extracts from Acacia confusa bark and heartwood. J Agric Food Chem 49: 3420-3424.

22. Nelson BC, Sharpless KE (2003) Quantification of the predominant monomeric catechins in baking chocolate standard reference material by LC/APCI-MS. $J$ Agric Food Chem 51: 531-537.

23. Zhu QY, Hammerstone JF, Lazarus SA, Schmitz HH, Keen CL (2003) Stabilizing effect of ascorbic acid on flavan-3-ols and dimeric procyanidins from cocoa. J Agric Food Chem 51: 828-833.

24. Misnawi, Jinap S, Nazamid S, Jamilah B (2002) Activation of remaining key enzymes in dried under-fermented cocoa beans and its effect on aroma precursor formation. Food Chemistry 78: 407-417.

25. Nazaruddin R, Seng LK, Hassan O, Said M (2006) Effect of pulp preconditioning on the content of polyphenols in cocoa beans (Theobroma cacao) during fermentation. Industrial Crops Product 24: 87-94.

26. Jinap S, Dimick PS, Hollender R (1995) Flavor evaluation of chocolate formulated from cocoa beans from different countries. Food Control 6: 105-110.

27. Azizah O, Abbe MMJ, Kong, KW, Amin I, Nawalyah AG, Ilham A (2010) Epicatechin content and antioxidant capacity of cocoa beans from four different countries. African Journal of Biotechnology 9: 1052-1059.

28. Demina NS, Lysenko SV (1996) [Collagenolytic enzymes synthesized by microorganisms]. Mikrobiologiia 65: 293-304

29. Kim Y, Uyama H, Kobayashi S (2004) Inhibition effects of (+)-catechinaldehyde polycondensates on proteinases causing proteolytic degradation of extracellular matrix. Biochemistry Biophysical Research Communications 320: 256-261.
30. Miao YP, Wen $R$, Aoshima $H$, Zhou PG (2004) Synthesis and antioxidative activity of 2-substituted phenyl-5-(3'-indolyl)-oxazole derivatives. Yao Xue Xue Bao 39: $37-40$

31. An BJ, Kwak JH, Park JM, Lee JY, Park TS, et al. (2005) Inhibition of enzyme activities and the antiwrinkle effect of polyphenol isolated from the persimmon leaf (Diospyros kaki folium) on human skin. Dermatol Surg 31: 848-854.

32. Baylac S, Racine P (2004) Inhibition of human leukocyte elastase by natural fragrant extracts of aromatic plants. International Journal of Aromatherapy 14 179-182.

33. Madhan B, Krishnamoorthy G, Rao JR, Nair BU (2007) Role of green tea polyphenols in the inhibition of collagenolytic activity by collagenase. Int $\mathrm{J}$ Biol Macromol 41: 16-22

34. Thring TS, Hili P, Naughton DP (2009) Anti-collagenase, anti-elastase and antioxidant activities of extracts from 21 plants. BMC Complement Altern Med 9: 27.

35. Meyer W, Neurand K, Radke B (1981) Elastic fibre arrangement in the skin of the pig. Arch Dermatol Res 270: 391-401.

36. Gil MI, Tomas-Barberan FA, Hess-Pierce B, Kader AA (2002) Antioxidant capacities, phenolic compounds, carotenoids, and vitamin $\mathrm{C}$ contents of nectarine, peach, and plum cultivars from California. Journal of Agricultural and Food Chemistry 50: 4976-4982.

37. Sun T, Ho CT (2005) Antioxidant activities of buckwheat extracts. Food Chemistry 90: 743-749.

38. Gorinstein S, LojekA, Ciz M, Pawelzik E, Delgado-Licon E, et al. (2008) Comparison of composition and antioxidant capacity of some cereals and pseudocereals. International Journal of Food Science and Technology 43: 629-637.

39. Gardner PT, White TAC, McPhail DB, Duthie GG (2000) The relative contributions of vitamin $\mathrm{C}$, carotenoids and phenolics to the antioxidant potential of fruit juices. Food Chemistry 68: 471-474. 